\title{
Adoption of Integrated Reporting: Reasons and Benefits-A Case Study Analysis
}

\author{
Filippo Vitolla ${ }^{1} \&$ Nicola Raimo ${ }^{1}$ \\ ${ }^{1}$ Department of Economics and Management, University LUM Jean Monnet, Italy \\ Correspondence: Filippo Vitolla, Department of Economics and Management, University LUM Jean Monnet, \\ Casamassima (BA), Italy. E-mail: vitolla@lum.it
}

Received: October 20, 2018

doi:10.5539/ijbm.v13n12p244
Accepted: November 17, 2018

Online Published: November 20, 2018

URL: https://doi.org/10.5539/ijbm.v13n12p244

\begin{abstract}
Integrated reporting is the new corporate reporting tool that includes financial and non-financial information in a single document. Although some studies describe the potential benefits of integrated reporting, this practice is still not widespread. One of the reasons for the limited diffusion is linked to the absence of empirical evidence that demonstrates the actual concreteness of these benefits for organizations that decide to adopt integrated reporting. This study analyses the process of adopting integrated reporting and the benefits associated with it through a case study. In particular, the case of Generali Group is analysed in the aim of highlighting the adoption path and the effects deriving from the implementation of integrated reporting in a context like the Italian one, still not very attentive to these issues. The findings show how the implementation of integrated reporting has been the result of a clear desire of top management and that the adoption of this practice has had a decidedly positive impact both from an internal and external point of view.
\end{abstract}

Keywords: Integrated reporting, IIRC, case study, process, reasons, benefits, Italian case

\section{Introduction}

Integrated reporting is an innovative and effective reporting tool that includes financial and non-financial information. It is basically considered a natural evolution of the corporate reporting movement, able to overcome the limits of traditional reporting and therefore able to better represent the value creation process. The adoption of integrated reporting provides several potential benefits to companies. However, this reporting tool is still scarce adopted by companies. This is certainly due to the lack of knowledge of the benefits associated with it and the presence of some critical issues regarding its adoption. One of the main difficulties for the companies is that related to the communication of the firm strategy, the business model and the value creation process. Some scholars have focused on identifying the main critical issues related to the adoption of integrated reporting. Specifically, Eccles and Serafeim (2015) and Pistoni and Songini (2015) underline how the lack of connectivity among strategy, business model, performance and future outlook, the presence of an informative gap in area such as stakeholder engagement, governance and materiality process and the limited practice of a third-party verification represent main critical issues that hinder the diffusion of integrated reporting. Most of the studies in the literature provide theoretical models aimed at explaining the benefits and problems related to integrated reporting or, alternatively, econometric models focused mainly on the identification of the determinants and consequences of integrated reporting. These studies are not able to provide empirical evidence regarding the process of approaching integrated reporting and the advantages connected to the adoption of this practice. It is therefore evident the need for further studies able to better describe the process of adoption of integrated reporting, the effects and benefits associated with the introduction of this practice. The aim of this work is to fill this gap through the study of a successful Italian case represented by Generali. In a context such as the Italian one of low diffusion of integrated reporting, the analysis of this case may represent a push for other companies to adopt this practice. Furthermore, this study, in addition to representing an important source of information for practitioners, can also be a starting point for future research by academics. The results show how the implementation of integrated reporting has had a decidedly positive impact. In fact, in addition to a greater ease of reading the documents, there were also favourable reactions from analysts who recognized a higher quality of disclosure. The stakeholder engagement activity also benefited from the adoption of integrated reporting. The remainder of the paper is organized as follows. Section 2 describes the theoretical background, Section 3 
contains the description of the methodology used, Section 4 presents the results obtained and, finally, Section 5 draws the conclusions.

\section{Theoretical Background}

In the last two decades, numerous scholars have turned their attention to the systems of accounting for the joint management and reporting of financial and non-financial performance. The path that led to the introduction of integrated reporting has been very long and several are the antecedents of this practice. However, the literature agrees on the identification of three main frameworks that precede the introduction of integrated reporting: balance scorecard, triple bottom line and sustainability reporting (e.g. Nixon \& Burns, 2012; Giovannoni \& Maraghini, 2013). However, these tools were not able to harmonize the various sources of corporate reporting and therefore failed to provide a holistic view of the company's performance. To this end, in 2010, the Prince's Accounting for Sustainability Project and the GRI formed (Vitolla, 2007), together with companies, investors, auditors, standard setters, and non-governmental organizations, the IIRC with the aim of drafting an internationally accepted Framework, which integrates financial and non-financial information. The aim was to create the basis for the development of a new model of corporate communication able to best represent the value creation process. Therefore, integrated reporting overcomes the dichotomous view of performance by providing a holistic view in which the ability to create value over time is the result of the actions carried out by the organization in transforming inputs into results (Adams \& Simnett, 2011; Abeysekera, 2013; Van Bommel, 2014; De Villiers et al., 2014; Stubbs \& Higgins, 2014). Integrated reporting allows companies to provide cumulative information on the process of creating value over time and satisfies the need for transparency and reliability of the market (Krzus, 2011; Eccles \& Serafeim, 2015). To this end, it focuses on different aspects of business performance and provides a complete view of how an organization creates value over time through financial, non-financial, qualitative and quantitative information (Eccles \& Krzus, 2010; Cheng et al., 2014; Higgins et al., 2014; Haller \& Van Staden, 2014; Girella, 2018). Integrated reporting shows how the interaction between these different information allows the creation of value over time (Abeysekera, 2013; De Villiers et al, 2014; Mohammad, 2017). This reporting tool could be seen as a simple aggregation of financial and non-financial information in a single document, but in reality it has a much more important role (Stubbs \& Higgins, 2014). Integrated reporting, in fact, represents a new theory of enterprise due to the introduction of new concepts such as capitals but above all integrated thinking (Paolucci \& Cerioni, 2017). According to the IIRC (2013), "Integrated thinking is the active consideration by an organization of the relationships between its various operating and functional units and the capitals that the organization uses or affects. Integrated thinking leads to integrated decision-making and actions that consider the creation of value over the short, medium and long term". The concept of integrated thinking implies that a managerial revolution within the organization is necessary for the implementation of integrated reporting (Busco et al., 2013; Stubbs \& Higgins, 2014; Thomson, 2015). The motivations that push companies to adopt integrated reporting are not only linked to the attention towards sustainability and ESG indicators. In fact, in the current context, where leadership models that align profit seeking and sustainability issues are increasingly needed, the benefits of integrated reporting are considerable. Integrated reporting is aimed primarily at stakeholders. Among these, investors are those who derive the greatest benefits from the publication of the integrated report thanks to the amount and quality of the information contained in the document. The greater transparency deriving from the publication of integrated reporting allows investors to make more informed investment choices, supported by greater knowledge of company performance. In this perspective, the main advantage, from an external perspective, is therefore to provide investors with financial and non-financial information on the process of creating value over time in a single document. However, some studies have identified several other benefits resulting from the adoption of integrated reporting (Black Sun, 2012; Blesener, 2014; Chartered Institute of Management Accountants, 2015). Integrated reporting from an internal perspective improves the ability to identify and assess risks and fosters the decision making process through the integration of ESG variables. Furthermore, it encourages the evaluation of company strategies, provides data on expected results, favours the comparison with competing companies, facilitates access to capital and credit markets, improves the quality of management and fosters dialogue among the various departments. From an external perspective, on the other hand, in addition to providing more information to investors, it offers a holistic overview of the company, improves the image of the company and encourages the construction of good relations with the stakeholders. However, despite these studies highlight the benefits of integrated reporting, in the world but especially in Italy, there are still very few companies that adopt this practice. In fact, while the IIRC has set itself the important objective of making integrated reporting mandatory by 2020, in Italy the adoption of integrated reporting by companies is struggling to take off mainly in the context of SMEs. Comodeca \& Almici (2017) underline how, despite the growing attention paid to integrated reporting, in Italy only six listed companies adopt this practice. However, Vitolla et al. (2018) argue that this situation is 
destined to change due to the introduction of Legislative Decree n. 254 of 30 December 2016, which represents an important push towards the adoption of integrated reporting by Italian companies. The poor adoption of integrated reporting by Italian companies is also due to the absence of empirical evidence that bears witness to the real benefits deriving from the adoption of this practice. This study aims to fill this gap. Therefore, in light of this, the research questions are the following:

RQ1: What are the reasons for the adoption of Integrated Reporting?

RQ2: What are the benefits of adopting Integrated Reporting?

\section{Research Methods}

In order to answer the research questions, we have conducted a single, in-depth case study. We have examined Generali S.p.A, the largest insurance group in Italy. In order to achieve the research objective, we have chosen to adopt this methodology for its ability to analyse a complex phenomenon that constitutes a relatively new field of research (Eisenhardt, 1989). We have also decided to use this methodology for its ability to identify causal relationships (Yin, 2009) and for the limited presence of studies on this topic that makes a qualitative research method more appropriate. In fact, the process of approaching integrated reporting and the advantages deriving from its adoption are little explored by previous studies. The selection of case study was not based on sampling logic, peculiar of surveys and of statistical methods. In fact, the case was chosen purposefully (Patton, 1990) because it allows to obtain detailed information in line with the objective of our research. The data collection is based on multiple sources. In fact, this analysis is based on both primary and secondary data. The primary data were collected from interviews by members of Generali's "Group Integrated Reporting and Cfo Hub" available on the web, while the secondary data were collected through the Generali website, through the content analysis of the integrated reports and through the reading of other documents. The combined use of primary data and secondary data makes empirical evidence more convincing and the research design more consistent. In fact, this allows the triangulation of the data (Yin, 2009). Furthermore, the joint use of primary and secondary data allowed us to validate the information collected and to identify further facets of the phenomenon analysed (Ryan et al., 2002). According to Denzin (1984) and Stake (1995) we have also used the method of triangulation of the researchers and theory triangulation. In order to answer the research questions, we have used a mixed methodological approach, following Yin (2009). Specifically, in order to answer the first research question we have used the illustrative case study method (Yin, 2009), and in order to answer the second research question, we have used the exploratory case study method (Yin, 2009).

\section{Findings}

\subsection{The Company and Its Reports}

Generali was founded in the city of Trieste on December 26, 1831. Today it is the largest insurance group in Italy and the third in the world. Generali is also the third Italian economic group by turnover, has over 70,000 employees and approximately 55 million customers. It operates in more than 60 countries and its main markets are Western Europe, North America and the Far East. The company is listed on the FTSE MIB index of the Milan Stock Exchange. Generali's approach to integrated reporting began in 2011, when it was included in the official IIRC pilot programme, which culminated with the publication of the first integrated report in 2013. Since then, Generali has no longer abandoned this reporting tool, publishing its integrated report in 2014, 2015, 2016 and 2017. Generali's commitment to integrated reporting is demonstrated by the participation in the <IR $>$ Network and by the help provided for the launch of the $<\mathrm{IR}>$ Insurance Network. Integrated reporting falls under the responsibility of the board of directors. However, the team responsible for preparing the report is the "Group integrated reporting and CFO hub". Four people work in this group: the head of this group, the head of the group IR framework and two employees. The CFO participates periodically in order to help define the content of the report. Other departments of the company provide information to the group. The various reports published by Generali from 2013 to 2017 present a narrative section that offers information requested by the IR framework and another narrative section that provides information in compliance with the financial reporting regulations, and consolidated financial statements. In all its reports, Generali declares to follow the IIRC principles for the preparation of the document (Assicurazioni Generali, 2013; 2014; 2015; 2016; 2017). The document structure is detailed in all the reports: in 2013 and 2014 in the section "About this report" (Assicurazioni Generali, 2013; 2014), in 2015 in the section "Notes on the management report" (Assicurazioni Generali, 2015) and in the 2016 and 2017 in the section "Notes to the report" (Assicurazioni Generali, 2016; 2017). The 2013 report lacked the section relating to the business model that was introduced in 2014, while the "Risk and opportunities" section was included in 2015. The reports prepared by Generali also present some sections not provided for by the IIRC framework. For example, the 2014 report includes a special section called "Insurance performance" while the 
2015 report includes a section called "Our history". A particularity of the 2017 report is represented by a further integration of non-financial information. In fact, in the 2017 report the company applied the Core \& More concept, using this as an opportunity to further innovate around their reporting, creating a truly holistic "core" report. Therefore, the 2017 report contains the material non-financial information that was previously available in the sustainability report. This information was selected thanks to an innovative materiality determination process. Therefore, the analysis of the reports shows how the common thread consists of the strategy, based on which the material aspects to be included in the reporting are identified. From a content point of view, the conceptual division of the International $<\mathrm{IR}>$ Framework is traced. After a brief summary of the main data characterizing the Group, the reports describe Vision, Mission and Values and external context. The Business Model goes into more detail about the company, illustrating governance, strategy and finally performance. Considering all the information given, it is easy to see how the power of information is greatly increased, since the integrated reports provide an overview of all the aspects that have an influence during the value creation process.

\subsection{The Reasons Behind the Adoption of Integrated Reporting and the Benefits Associated with It}

The decision to adopt integrated reporting is a big step towards greater efficiency and greater transparency. Integrated reporting is not simply the evolution of a report, but is the result of a long journey towards greater business integration (Vitolla et al., 2017). Within Generali, this path began thanks to the curiosity of the board of directors who sponsored a medium-term project called Corporate Reporting Evolution. This led to the publication of the first integrated report in 2013, obtained by combining the regulatory requirements with the principles of the International $<\mathrm{IR}>$ Framework in a single document. Regarding the process of approaching integrated reporting, the Head of Group Integrated Reporting \& CFO Hub declares:

"Journey dates back to 2011, when the Board asked the CFO to have an insight on the newly born concept of One Report, the ancestor of the Integrated Report"

Integrated Reporting has intrinsically changed Generali, as well as improving its perception by external stakeholders. First of all, the integrated Report succeeded in highlighting and promoting integrated thinking, the real driving force behind the process that led to the creation of an integrated report. Integrated thinking represents a radical change in the way Generali intends the business. In this regard, the Head of Group Integrated Reporting \& CFO Hub declares:

"The biggest challenge we have faced in Generali was to secure the initial engagement of the other functions in thinking and reporting in an integrated way"

Improvements in intra-company communication are also important and noteworthy. The fact of having to provide feedback on their activities for the purpose of preparing the integrated report, and the collaboration of the Group Integrated Reporting \& CFO Hub department with various other areas such as Investor \& Rating Agency Relations and Group Communications \& Public Affairs for the drafting of the document has increased the interaction between the areas, generating an improvement in the internal information flow. The Corporate Reporting Evolution also aims at the synthesis. Integrated thinking rooted in Generali has allowed experiments concerning the use of the $<\mathrm{IR}>$ Framework in different fields compared to the annual disclosure. With reference to regulatory financial reporting, the application of integrated thinking, its concepts of materiality, conciseness and transparency have led to the rationalization of the quarterly financial report. The quarterly report, in the 2013 version, consisted of an average of 110 pages, while in 2014 only 15 pages. Despite this synthesis process, all the information required at the regulatory level has been included in other communication media, such as the Financial Supplement, thus guaranteeing the new document a comprehensive information capacity and increased accessibility in favor of a wider range of stakeholders. This process of summarizing the information, both for the quarterly reports and for the annual report, is linked to the decision by the management to make the reporting system more attractive and suitable for an audience not only composed of highly qualified operators. To do this, Generali has embraced the cause of IIRC. Demonstrating the validity of the principles of the Framework, Generali has received numerous positive feedback regarding the work of synthesis. Analysts particularly appreciated the brevity and materiality of corporate communication, even citing this improvement in their reports regarding Generali's economic and financial performance. The academic world has responded equally positively, and the feedback obtained from the collaboration with various Italian universities have also provided useful hints for improvement in the preparation of the integrated report. Generali's employees also expressed positive opinions on the integrated report, praising above all the greater usability of the document. The integrated report is therefore no longer a document used only by operators in the sector, but has spread to a wider range of stakeholders than before. Integrated thinking has also been applied internally starting from the Group Integrated Reporting \& CFO 
Hub area. In this case the concepts expressed by the Framework have been applied at the level of the individual department in such a way as to improve the involvement of the population of the organizational unit with the strategic objectives of the unit or of the company as a whole. The Internal Integrated Report is made up of around twenty pages containing crucial elements for the corporate activity, adapted to the context of the individual area, such as mission, organization, strategic objectives and performance. It represents a unique case within the world, and has aroused considerable curiosity from the academic world and also from the IIRC. In conclusion, it is evident that the intrinsic value of integrated reporting for Generali is very high. Although a consistent and constant effort is necessary for the implementation of integrated reporting, especially in the early stages, the benefits obtained are greater than the efforts required to implement it. The integrated report can be considered a tool that improves the personal and professional life of employees, as well as being a valid tool for communicating company objectives and performance.

\section{Conclusions}

The objective of our work was to analyse the process of adopting integrated reporting and the benefits deriving from the implementation of this practice. To this end, we carried out an in-depth analysis of the Generali Group through illustrative and exploratory case study methods. The results show, first of all, that the process of implementing integrated reporting is the result of a clear desire of top management. This demonstrates the importance of corporate culture in the process of adopting integrated reporting (Vitolla et al., 2016). Therefore, the pressures of external stakeholders are not enough, but it is necessary that the change starts from within the company through a corporate culture devoted to sustainability and transparency. Secondly, the results show that the adoption of integrated reporting has had positive impact on the company. In fact, favourable reactions were recorded by analysts who recognized a higher quality of external reporting combined with a greater readability of documents. The stakeholder engagement activity also benefited from the adoption of integrated reporting. Generali has indeed received attention from both universities and the IIRC. Following the adoption of integrated reporting there are several conferences to which the company is invited to participate. Moreover, the implementation of integrated reporting has had positive effects even within the same company with a greater involvement of employees. The results obtained confirm what has been said in the literature regarding the positive effects of integrated reporting. The most surprising aspect is that related to the strong positive impacts within the company, since generally reporting is considered an instrument that is mainly addressed to external stakeholders. This work contributes to the literature on the topic by providing empirical evidence on the positive effects of integrated reporting and shedding light on the way in which the implementation process of this practice is launched. However, this paper presents the intrinsic limit of the case study methodology related to the difficulties in generalizing the results. Therefore, future research can use a multiple case study or alternatively test, through econometric models, specific benefits, such as the positive impact on the firm value or on the cost of capital.

\section{References}

Abeysekera, I. (2013). A template for integrated reporting. Journal of Intellectual Capital, 14(2), 227-245. https://doi.org/10.1108/14691931311323869

Adams, S., \& Simnett, R. (2011). Integrated Reporting: An opportunity for Australia's not for profit sector. Australian Accounting Review, 21(3), 292-301. http://dx.doi.org/10.1111/j.1835-2561.2011.00143.x

Assicurazioni, G. (2013). Annual integrated report 2013.

Assicurazioni, G. (2014). Annual integrated report 2014.

Assicurazioni, G. (2015). Annual integrated report 2015.

Assicurazioni, G. (2016). Annual integrated report 2016.

Assicurazioni, G. (2017). Annual integrated report 2017.

Black, S. (2012). Understanding transformation: Building the business case for integrated reporting. London: International Integrated Reporting Council.

Blesener, S. (2014). Realizing the benefits: The impact of integrated reporting. London: International Integrated Reporting Council.

Busco, C., Frigo, M. L., Quattrone, P., \& Riccaboni, A. (2013). Integrated Reporting. Concepts and cases that Redefine Corporate Accountability. London: Springer.

Camodeca, R., \& Almici, A. (2017). Implementing Integrated Reporting: Case Studies from the Italian Listed Companies. Accounting and Finance Research, 6(2), 121. https://doi.org/10.5430/afr.v6n2p121 
Chartered Institute of Management Accountants (CIMA). (2015). Integrated reporting in the Public Sector. Retrieved from

Cheng, M., Green, W., Conradie, P., Konishi, N., \& Romi, A. (2014). The International Integrated Reporting framework: key issues and future research opportunities. Journal of International Financial Management \& Accounting, 25(1), 90-119. https://doi.org/10.1111/jifm.12015

De Villiers, C., Rinaldi, L., \& Unerman, J. (2014). Integrated Reporting: insights, gaps and an agenda for future research. Accounting, Auditing and Accountability Journal, 27(7), 1042-1067. https://doi.org/10.1108/AAAJ-06-2014-1736

Denzin, N. (1984). The Research Act. Prentice Hall, Englewood Cliffs, NJ.

Eccles, R. G., \& Krzus, M. P. (2010). One Report. Integrated Reporting for a Sustainable Strategy. Hoboken: John Wiley \& Sons.

Eccles, R. G., \& Serafeim, G. (2015). Corporate and integrated reporting. Corporate Stewardship: Achieving Sustainable Effectiveness, 156.

Eisenhardt, K. M. (1989). Building theories from case study research. Academy of management review, 14(4), 532-550. https://doi.org/10.5465/amr.1989.4308385

Giovannoni, E., \& Pia Maraghini, M. (2013). The challenges of integrated performance measurement systems: Integrating mechanisms for integrated measures. Accounting, Auditing \& Accountability Journal, 26(6). https://doi.org/10.1108/AAAJ-04-2013-1312

Girella, L. (2018). The boundaries in financial and non-financial reporting. A comparative analysis of their constitutive roles. New York: Routledge.

Haller, A., \& Van Staden, C. (2014). The value added statement-an appropriate instrument for Integrated Reporting. Accounting, Auditing \& Accountability Journal, 27(7), 1190-1216. http://dx.doi.org/10.1108/AAAJ-04-2013-1307

Higgins, C., Stubbs, W., \& Love, T. (2014). Walking the talk(s): Organisational narratives of integrated reporting. Accounting, Auditing \& Accountability Journal, 27(7), 1090-1119. https://doi.org/10.1108/AAAJ-04-2013-1303.

IIRC. (2013). International $\quad<\mathrm{IR}>\quad$ Framework. $\quad$ Retrieved from http://integratedreporting.org/resource/international-ir-framework

Krzus, M. P. (2011). Integrated reporting: if not now, when. Zeitschrift für internationale Rechnungslegung, 6, 271-276.

Mohammad, E. H. (2017). Why company adopt Integrated Reporting? International Journal of Economics and Financial Issues, 7(1), 241-248.

Nixon, B., \& Burns, J. (2012). The paradox of strategic management accounting. Management Accounting Research, 23(4), 229-244. https://doi.org/10.1016/j.mar.2012.09.004

Paolucci, G., \& Cerioni, E. (2017). Integrated reporting and Italian companies: An empirical investigation. International Journal of Business and Management, 12(9), 221. https://doi.org/10.5539/ijbm.v12n9p221.

Patton, M. Q. (1990). Qualitative evaluation and research methods. SAGE Publications, inc.

Pistoni, A., \& Songini, L. (2015). New trends and directions in CSD: the integrated reporting. In Sustainability Disclosure: State of the Art and New Directions (pp. 81-105). Emerald Group Publishing Limited.

Ryan, B., Scapens, R. W., \& Theobald, M. (2002). Research Method and Methodology in Finance and Accounting. London: Thomson Learning.

Stake, R. E. (1995). The art of case study research.

Stubbs, W., \& Higgins, C. (2014). Integrated Reporting and internal mechanisms of change. Accounting, Auditing and Accountability Journal, 27(7), 1068-1089. https://doi.org/10.1108/AAAJ-03-2013-1279

Thomson, I. (2015). But does sustainability need capitalism or an integrated report? A commentary on "The International Integrated Reporting Council: A story of failure. Critical Perspectives on Accounting, 27, 18-22. https://dx.doi.org/10.1016/j.cpa.2014.07.003 1045-2354

Van Bommel, K. (2014). Towards a legitimate compromise? An exploration of Integrated Reporting in the Netherlands. Accounting, Auditing and Accountability Journal, 27(7), 1157-1189. 
https://doi:10.1108/AAAJ-04-2013-1309.

Vitolla, F. (2007). Le linee guida della Global Reporting Initiative per la redazione dei report di sostenibilità. Rivista dei Dottori Commercialisti, 58(4), 663-690.

Vitolla, F., Raimo, N., \& De Nuccio, E. (2018). Integrated Reporting: Development and State of Art-The Italian Case in the International Context. International Journal of Business and Management, 13(11), 233-240. https://doi.org/10.5539/ijbm.v13n11p233

Vitolla, F., Rubino, M., \& Garzoni A. (2016). Integrated corporate social responsibility: Driving factors and means of integration - a multiple case study analysis. Journal of Management Development, 35(10), 1323-1343. https://doi.org/10.1108/JMD-08-2015-0113

Vitolla, F., Rubino, M., \& Garzoni A. (2017). The integration of CSR into strategic management: A dynamic approach based on social management philosophy. Corporate Governance: The International Journal of Business in Society, 17(1), 89-116. https://doi.org/10.1108/CG-03-2016-0064

Yin, R. K. (2009). Case Study Research: Design and Methods. London: Sage Publication.

\section{Copyrights}

Copyright for this article is retained by the author(s), with first publication rights granted to the journal.

This is an open-access article distributed under the terms and conditions of the Creative Commons Attribution license (http://creativecommons.org/licenses/by/4.0/). 